\title{
Self-perception of personality characteristics and the Type A behavior pattern
}

\author{
LORETTA MCGREGOR \\ Southern Arkansas University, Magnolia, Arkansas \\ and \\ MARCIA EVELEIGH, JOHN C. SYLER, and STEPHEN F. DAVIS \\ Emporia State University, Emporia, Kansas
}

\begin{abstract}
Two hundred fifty-one undergraduate college students ( 172 women, 79 men) were administered the modified Jenkins Activity Survey (JAS) and the Self-Perception Profile for College Students (SPP) to measure Type A characteristics and the self-perception of selected personality characteristics, respectively. Prior to analysis of the SPP scores, the subjects were categorized as Type A or Type B on the basis of their JAS scores. Analysis of the 13 SPP domains yielded several significant gender and Type A/B effects. The significant gender effects are seen as reflecting the perpetuation of sex-role stereotypes. Significant Type A/B effects indicate that these individuals differ in terms of how they perceive several aspects of their personality.
\end{abstract}

The Type A behavior pattern has been characterized (Friedman \& Rosenman, 1977) by the following traits: (1) a sense of time urgency, (2) competitive achievement striving, and (3) high levels of aggressiveness and/or freefloating hostility. In contrast, Type B individuals are defined by the relative absence of these Type A characteristics.

All of the Type A characteristics are seen as mechanisms by which the individual attempts to maintain control over the surrounding environment. Any situation that is perceived as a threat to the individual's control results in an intensification of these mechanisms. In support of this contention, Glass (1977) demonstrated that Type A individuals displayed greater reactions than did Type Bs to uncontrollable events that were very salient, whereas the opposite was true for events of low salience. Likewise, Type As have rated themselves as more helpless and presumably more threatened by lack of control in high-stress/no-escape situations than in high-stress/escape situations.

Corroborating the time-urgency characteristic, Glass, Snyder, and Hollis (1974) demonstrated that Type A individuals displayed greater impairment on a task requiring a response delay than did Type Bs. The Type A subjects consistently overestimated the passage of time and responded before the delay interval had timed out.

In support of the aggressiveness characteristic, Type A adults were shown to be significantly more aggressive than Type Bs when provoked by an annoying confederate or by a frustrating task (Carver \& Glass, 1978). Elements of

Portions of this paper were presented at the 1990 meeting of the Association for Psychological and Educational Research in Hays, KS. Reprints may be obtained from Stephen F. Davis, Department of Psychology, Emporia State University, Emporia, KS 66801. competitive achievement striving also have been reported in numerous studies. For example, to continue a tiring but challenging task, Type $A$ individuals have repeatedly suppressed fatigue and performed closer to their endurance levels than have Type Bs (Carver, Coleman, \& Glass, 1976).

Likewise, data relating the Type A behavior pattern to other personality characteristics have been reported. Tramill, Kleinhammer-Tramill, Davis, Parks, and Alexander (1984) found that extreme Type A individuals displayed higher death anxiety and manifest anxiety scores than did Type B individuals. Corroborating the 1984 data, Tramill, Kleinhammer-Tramill, Davis, and Parks (1985) also found that Type A individuals had higher death anxiety scores than did Type B individuals. These investigators also reported the occurrence of a negative relationship between Type A characteristics and level of self-esteem. Additionally, Davis, Hill, Walkup, and Russin (1987) reported that extreme Type A individuals possessed a "morning" personality, while extreme Type B individuals possessed an "evening" personality.

It is noteworthy that those studies relating personality and Type A characteristics (e.g., Davis et al., 1987; Tramill et al., 1985; Tramill et al., 1984) have evaluated the personality characteristic(s) under consideration as if they were measurable commodities possessed to greater or lesser degrees. On the other hand, no study has simultaneously evaluated differences in the self-perceptions of Type A and Type B individuals on several personality domains. Through the administration of the modified Jenkins Activity Survey to measure Type A/B characteristics, and the Self-Perception Profile for College Students to measure self-perception of selected personality characteristics, the present study sought to provide preliminary data on this topic. 


\section{METHOD}

\section{Subjects}

The subjects were 251 undergraduate college students ( 172 women, 79 men) enrolled at a medium-sized, regional state university. All subjects volunteered to participate in the study.

\section{Testing Instruments}

The testing instruments consisted of the modified Jenkins Activity Survey (JAS) and the Self-Perception Profile for College Students (SPP). The JAS (Krantz, Glass, \& Snyder, 1974) is a 21-item, multiple-choice questionnaire that has a normative mean of 8 and a standard deviation of 4 .

The SPP is a 54-item scale developed by Neeman and Harter (1986) to measure college students' perceptions of themselves. The SPP provides scores measuring a person's perceived ability in the following 13 personality domains: creativity, intellectual ability, scholastic competence, job competence, athletic competence, appearance, romantic relationships, social acceptance, close friends, parent relationships, humor, morality, and global self-worth

\section{Procedure}

Test administration took place during regularly scheduled class sessions. Each student was given an informed consent form. General instructions concerning confidentiality rights were presented by the experimenter. After the consent forms had been returned, the subjects were given a self-administering booklet consisting of the JAS and SPP. The subject's gender was indicated. All questionnaires were completed anonymously. Booklets were collected when all subjects had finished. Even though no time limit was imposed, all subjects completed both questionnaires within $20 \mathrm{~min}$

\section{RESULTS}

Prior to analysis of the SPP scores, the subjects were grouped, by gender, into the following Type A/B categories on the basis of JAS scores: B+ (0-4), B - (5-7), $A-(9-11)$, and $A+(12$ and higher). All subjects who scored at the normative mean of 8 were excluded from further analysis. Upon completion of assignment to the appropriate Type A/B category, the following samples remained for further analysis: B + (28 women, 9 men $)$, B (54 women, 20 men), A - (45 women, 28 men), A + (45 women, 22 men).

A separate $2 \times 4$ unweighted means analysis of variance, incorporating gender (male vs. female) and Type $A / B$ classification $(\mathrm{B}+, \mathrm{B}-, \mathrm{A}-$, and $\mathrm{A}+)$, was performed on the data for each domain measured by the SPP. For purposes of clarity, significant results are presented in two categories: (1) gender-related effects and (2) effects related to differences between the Type A/B personality types. In each instance, a brief description of the nature of the SPP domain is provided.

\section{Gender Effects}

Social acceptance. This subscale is concerned with being satisfied with one's social skills and the ability to make friends easily. The men were found to have higher social acceptance scores than did the women $[F(1,243)=6.656$, $p<.01]$.

Appearance. This subscale focuses on whether one thinks that he/she is physically attractive and feels happy with oneself. The men scored higher than did the women on this subscale $[F(1,243)=7.853, p=.005]$.

Intellectual ability. This subscale measures general intellectual competence. The men scored higher than did the women $[F(1,243)=4.369, p=.035]$.

Creativity. This subscale measures the student's perception of his/her ability to be creative or inventive. The creativity scores of the men were higher than those of the women $[F(1,243)=14.284, p<.001]$.

Athletic competence. This subscale seeks to gain knowledge of whether one feels he/she is good at physical activities and sports. The men scored higher than did the women on this subscale $[F(1,243)=11.451, p=.001]$.

Morality. Items from this subscale ask whether one feels his/her behavior is moral. The women scored higher on the morality subscale than did the men.

\section{Significant Type A/B Effects}

The results of Newman-Keuls tests performed subsequent to omnibus $F$ ratios indicated that, in all instances, the scores of the $\mathrm{A}$ - and $\mathrm{A}+$ subjects were significantly (lowest $p<.05$ ) higher than those of the B- and B+ subjects. However, no significant differences existed between the two Type A categories and between the two Type B categories.

Scholastic competence. This subscale questions whether one feels competent that he/she is mastering coursework $[F(3,243)=6.666, p<.001]$.

Intellectual ability. This subscale measures general intellectual competence $[F(3,243)=3.226, p=.022]$.

Morality. Items from this subscale ask whether one feels his/her behavior is moral $[F(3,243)=3.445, p=.017]$.

Global self-worth. This subscale taps one's general feeling about the self $[F(3,243)=3.665, p=.017]$.

\section{DISCUSSION}

Clearly, this project yielded several significant effects of potential interest. The significant gender effects indicate that certain sex-role stereotypes may yet be operative in our society. For example, the significantly higher appearance scores reported by the men may have been prompted by the plethora of "macho" role models that currently permeate the popular media. Likewise, the sports section of any newspaper or television newscast illustrates why the men in our study perceived themselves as having superior athletic ability. The finding that women had significantly higher morality scores than did the men also may reflect the presence of a sex-role stereotype. It is encouraging to note that the first two results replicate data reported by McGregor, Mayleben, Buzzanga, Davis, and Becker (in press).

The higher intellectual ability and creativity scores reported by the men also replicate the McGregor et al. (in press) data. As noted by McGregor et al., these data are supportive of the proposal (Callahan, 1979, 1981; Eccles, 1985) that social and cultural expectations are a preferred explanation for the finding that more men than women, of the same age, have achieved outstanding status or recognition and are considered to be gifted or creative.

Turning to the domains in which the Type A and Type B individuals differed, some patterns or trends also are discernible. First, Type A individuals have a higher opinion of their intellectual abilities and scholastic competence than do their Type B counterparts. This finding may be seen as supporting the competitive nature of the Type $A$ individual. On the basis of this logic, it is predicted that Type As would have superior 
academic records. This prediction presents another interesting possibility for continued research in this area.

The exact nature or meaning of the perceived superiority of the Type As in the morality domain is not readily apparent. This result may be interpreted to reflect that Type As feel that their behaviors are appropriate.

Finally, it is especially noteworthy that the Type A individuals had a significantly higher self-perception of their global self-worth than did the Type B individuals. Clearly, Type As are individuals who expect to succeed in what they undertake.

On the other hand, it is just as important to note that significant differences between the Type As and the Type Bs were not recorded in several domains-job competence, social acceptance, appearance, close friendships, humor, creativity, parent relationships, and athletic competence. Why these domains did not serve to differentiate between these two personality types is not clear. The need to replicate the present data is clear. On the other hand, it is equally clear that Type As and Type Bs do have different perceptions of themselves.

\section{REFERENCES}

Callahan, C. M. (1979). Gifted women. In A. H. Passow (Ed.), The 78th yearbook of the National Society of the Study of Education, Part I. The gifted and talented: Their education and development. Chicago: University of Chicago Press.

Callahan, C. M. (1981). Superior abilities. In J. M. Kaufman \& D. P. Hallahan (Eds.), Handbook of special education. Englewood Cliffs, NJ: Prentice-Hall.

Carver, C. S., Coleman, A. E., \& Glass, D. C. (1976). The coronaryprone behavior pattern and the suppression of fatigue on a treadmill test. Journal of Personality \& Social Psychology, 33, 460-466.

CARver, C. S., \& Glass, D. C. (1978). Coronary-prone behavior pattern and interpersonal aggression. Journal of Personality \& Social Psychology, 36, 361-366.
Davis, S. F., Hill, S., WalkuP, T., \& Russin, R. (1987). The relationship between the Type $\mathrm{A} / \mathrm{B}$ behavior pattern and the morning/evening personality in college students. College Student Journal, 20, 417-419.

ECCLES, J. S. (1985). Why doesn't Jane run? Sex differences in education and occupational patterns. In F. D. Horowitz \& M. O'Brien (Eds.), The gifted and talented: Developmental perspectives. Washington, DC: American Psychological Association.

Friedman, M., \& Rosenman, R. H. (1977). The key cause: Type A behavior pattern. In A. Monat \& R. H. Lazrus (Eds.), Stress and coping (pp. 203-212). New York: Columbia University Press.

GLass, D. C. (1977). Behavior patterns, stress, and coronary disease. Hillsdale, NJ: Erlbaum.

Glass, D. C., SNyder, M. L., \& Hollis, J. F. (1974). Time urgency and the Type A coronary-prone behavior pattern. Journal of Applied Social Psychology, 4, 125-140.

Krantz, D. S., Glass, D. C., \& SNyder, M. L. (1974). Helplessness, stress level, and the coronary-prone behavior pattern. Journal of Experimental Social Psychology, 10, 284-300.

McGregor, L. N., Mayleben, M. A., Buzzanga, V. L., Davis, S. F., \& BECKER, A. H. (in press). Selected personality characteristics of first-generation college students. College Student Journal.

Neeman, J., \& Harter, S. (1986). Manual for the Self-Perception Profile for College Students. Denver: University of Denver.

Tramill, J. L., Kleinhammer-Tramill, P. J., Davis, S. F., \& Parks, C. S. (1985). The relationship between Type A and Type B behaviors and level of self-esteem. Psychological Record, 35, 323-327.

Tramill, J. L., Kleinhammer-Tramill, P. J., Davis, S. F., Parks, C. S., \& AleXander, D. (1984). The relationship between the Type A behavior pattern, fear of death, and manifest anxiety. Bulletin of the Psychonomic Society, 22, 42-44.

(Manuscript received January 22, 1991.) 